living, and well ; three who have held office in the dispensary since the year 1867 are also well ; and the present senior dispenser has been with us for ten years. Many others have been in this department since the opening of the hospital, but only one has been known to have been consumptive.

The resident clinical assistants, of whom we are able to obtain reliable information, amount to seventy-eight in number. Three of these are said to be phthisical ; but only one has been known to have died of phthisis. This gentleman I knew intimately ; he was always of consumptive appearance, and one of his sisters had died of phthisis.

Our resident medical officer, Mr. Edwards, to whom I am indebted for the statistics I am now giving, has held office for more than twentyone years ; and all those who know him can testify both to his continued health and his undiminished energy and usefulness. The present matron has also been in her office for more than twenty-one years, during which long period her health has been excellent.

The present secretary has been at his post for fifteen years; and his only predecessor, who is still alive and well, had held the same office for sixteen years. The assistant-secretary has been at his duties within the hospital for eighteen years; and a clerk-whose office it is to register the out-patients, and who must, on that account, be exposed to an unusually great extent to phthisical contagion, did such existhas been at his work for five years. I am happy to add that all of the above are now in excellent health.

The present chaplain has been with us for twenty-two years; and his two predecessors are still living. Happily all of them are well.

Of the staff of physicians and assistant-physicians-nineteen in number-one only has been affected with phthisis; and he was a young man of delicate and decidedly consumptive aspect. The period of office which some of us have had is unusually long. Of the present physicians, two have been upon the staff twenty-four years each; one for seventeen years ; one fur thirteen years; one for nine years; and one for five years. The late senior physician, who resigned only three years ago, had been attached to the hospital, and in constant work there, from its very foundation. Two of the former physicians who resigned their appointments, and subsequently died of disease quite distinct from phthisis, had held office in the hospital for fifteen and nineteen years respectively.

I have elsewhere given my experience of the statistics of phthisis, in one of our chief metropolitan general hospitals; and the subsequent observation which I have had only tends to convince me the more that the evidence in this respect is greatly in favour of the Hospital for Consumption.

With the above facts before us, must it not appear to all believers in the doctrine of phthisis originating in a special and contagious poison, that a residence in the Consumption Hospital, and long-continued working in its wards, is a very good way indeed not to catch the disease?

\section{THE TREATMENT OF PUERPERAL ECLAMPSIA *}

BY A. B. STEELE, L.K.Q C.P.,

Lecturer on Midwifery in the Liverpool Royal Infirmary School of Medicine.

THERE is no complication of labour which causes so much terror to bystanders, or demands greater calmness and self-possession on the part of the practitioner, or requires more prompt, decisive, and discriminating treatment, than an attack of convulsions; and yet there are few of the accidents of childbirth, the appropriate management of which is the subject of such diverse and conflicting opinions. Until a comparatively recent period, there was almost an universal agreement as to the necessity of free general depletion in all the severe forms of this affection. Latterly, however, the necessity and even the propriety of the use of the lancet in this disease has been called in question. Chloroform, which undoubtedly has considerable control in many instances over the paroxysms, has been considered by some to be a specific remedy, while others have advocated, in all cases of puerperal eclampsia, manual dilatation of the os uteri and speedy delivery; others, again, have found perforation of the membranes and the evacuation of the liquor amnii, where that fluid has been in excess, sufficient to diminish and ultimately to arrest entirely the convulsions. It is probable that these differences of opinion are to a great extent apparent only, and that theoretical disagreement as to principles would frequently find a solution in a much greater uniformity in actual practice than might be supposed. To paraphrase an expression of Dr. Billing, in his Principlis of Midicinc, "Because it is right for me to bleed my

* Read in the Midwifery Section at the Annual Meeting of the British Medical Association at Birmingham, August 1872 . patient in convulsions, it does not follow that it would be right for you to bleed your patient in the same disease". In fact, this formidable affection is not to be managed according to any fixed or undeviating formula, but requires for its successful treatment a pure system of eclecticism.

The rule laid down by a large number of high authorities, that copious blood-letting is the first and great remedy, the extent to which it is to be carried being regulated chiefly by the violence and frequency of the fits, is founded upon a twofold fallacy : first, an entire repudiation of widely differing types and phases which the disease assumes; and secondly, a misapprehension of its true nature and of the effects of blood-letting upon it. Convulsions have been attributed to an overloaded state of the cerebral vessels, as in apoplexy, to relieve which copious evacuation is necessary, when in truth, as was shown by Marshall Hall, eclampsia is a disease not of the brain at all, but of the true spinal system ; and Trousseau and Niemeyer have also maintained that congestion of the brain in convulsions is an effect rather than a cause.

The propriety and extent of blood-letting must be estimated not by the violence of the disease, but by the state of the circulation in the intervals of the paroxysms. In an overloaded condition of the vascular system, blood-letting acts as a direct sedative to the spinal cord; in the opposite condition, that of anæmia, or when carried too far, it only adds to the mischief, by increasing the already irritable condition of the spinal centres resulting from their anæmic condition; the pathology of the remedy, as Dr. Tyler Smith has quaintly said, thus closely trenching upon its therapeutic effect. There is, however, one condition in which blood-letting acts directly through its influence on the cerebral vessels-namely, when serous or sanguineous effusion or overdistention of the brain itself causes counter-pressure on the medulla oblongata, and thus indirectly gives rise to convulsions by spinal irritation.

There is yet a further most important effect of blood-letting not generally recognised-namely, its preservative infuence in lessening the turgidity of the vessels of the head caused by recurring paroxysms, and which may lead to fatal cerebral congestion or effusion. Thus blood-letting in plethoric states of the circulation is curative in its action on the spinal marrow, preservative in its action upon the brain.

There is a common belief that in the uræmic form of convulsions blood-letting is less effective, or altogether inadmissible : this I believe to be a mistake. Where the other indications for depletion are present, the fact that the blood is charged with a poisonous element is an additional reason in favour of lessening the amount of the circulating fluid, and thus at once eliminating an appreciable quantity of the deleterious matter. Dr. Richardson has recorded the beneficial effects of blood-letting in the convulsions which occur in albuminuria, which he explains on the ground just stated.

The necessity for bleeding more copiously in this than in most other diseases, depends upon the special condition of the vascular system in the parturient female. We know that loss of blood produces little or no effect upon the maternal pulse until it is carried beyond the point which exhausts the surplus blood, so to speak, required for the maintenance of the uterine and fetal circulation.

Chloroform is unquestionably a valuable remedy in convulsions; but it is neither a specific, nor can it supersede the necessity for bloodletting in plethoric conditions of the system. Nor do I believe that is will, as has been asserted, invariably lessen the violence or frequency of the paroxysms. These being truly reflex in their character, and the influence of chloroform over reflex action being limited, after free depletion, or in cases where depletion is contraindicated, it is most useful. Early and speedy delivery is undoubtedly the best treatment in certain conditions-namely, when, by the eliminative process of reasoning, we arrive at the conclusion that distension of the uterus or the presence of the ovum is the exciting cause of the fits; but the view that it should be adopted as an universal rule is shown to be a fallacy by the following facts. Convulsions in some cases do not occur until after delivery ; more often they persist and even increase in intensity after delivery. This practice has been recommended on the ground that the uræmic condition speedily proves fatal, first to the child and then to the mother. But many cases are on record where convulsions exist when there is no evidence of uræmia at all ; and again, even when convulsions have lasted for many hours, the case has terminated favour. ably both to mother and child. I believe that the death of the foetus, when it occurs, is in most instances to be attributed to asphyxia, from interruption of the placental circulation, from the violence and frequency of the paroxysms, and not to uræmia.

Against indiscriminate and hasty interference with the natural course of labour in convulsions there are strong grounds, both theoretical and practical. Any additional source of reflex irritation may frequently 
prove a direct cause of convulsive action; and the carefully recorded statistics of Dr. Murphy show that the mortality in this disease is much greater when labour has been artificially accelerated than when it has been left to the natural efforts.

In conclusion, I need scarcely say that I have given but an imperfect and incomplete account of a very comprehensive subject. Enough, however, I would fain hope, has been said to furnish ample scope for an interesting and instructive discussion on a question of much importance to obstetricians.

\section{RESTRA I N T I N I N S A I T Y.* \\ By STANLEY HAYNES, M.D., Malvern.}

THE propriety of mechanical restriction has lately attracted some attention ; it was questioned in the treatment of patients becoming maniacal during variola, and, quite recently, with regard to the treatment of otherwise unmanageable, suicidal, violent, or destructive insane persons.

As this topic is now brought forward for the purpose of eliciting discussion, and the expression of medical opinion upon a quastio vexata in our profession, I abstain from here noticing the excesses to which mechanical restraint used to be subject and is now carried, or from recording the judgments of authorities in favour of or against it.

As medical men, we must put aside all mere sentimentality in the consideration of this subject, and confine our attention to the inquiry whether our patients will be benefited or injured by the imposition of corporal restriction. To avoid irrelevant discussion, perhaps it will be well to define the meaning of restraint, as applied to our treatment of patients. Restraint is moral, intellectual, medicinal, or corporeal. Moral and intellectual I propose to exclude from this investigation. By medicinal restraint $I$ understand the conditions in which patients can be placed by the administration of narcotics, sedatives, or nauseants. Corporeal restriction is of two kinds-by seclusion, and by mechanical appliances. Seclusion, as a form of restraint, is solitary, undesired con finement ; when patients request to be kept apart from others, it is unfair to consider them as restrained. Restraint by some appliance, i.e., "estriction of motion in any desired direction by some kind of garment, is effected by means of sheets, camisole (or "strait waistcoat") or glove.

It is to be assumed that all practitioners will agree in the propriety of restraint-other means failing-in surgical cases (e.g. when a person has a self-inflicted wound and is striving to pull it open); and it will probably be at once conceded that in some of the maniacal conditions consequent on variola, typhus, and other febrile states, we are justified in mechanically repressing our patients from injuring themselves and others, by fastening a sheet across the patients and under the sides of the beds; such patients are too weak to be kept in bed by the hands of nurses, however careful and gentle. There will be more difference of opinion concerning the restraint of insane persons, the lunacy authorities being, naturally, antagonistic to the principle, and the majority of British asylum superintendents condemning it ; their example is being followed by some of the German alienists, and it is to be sincerely hoped mechanical restrictions will soon be as rare in America and on the European continent as here.

As the question now stands, mechanical restraint is the bugbear of lunacy practice; we have rushed from too much restraint to too little, if we are never to use it under any circumstances, as some extremists uphold. We can no more advocate prevalence of physical control than we can of depressing procedures; but there can be no doubt there are some very exceptional cases in which the employment of mechanical restraint is the most advisable method we can adopt, and, therefore, our duty as physicians and men. The system of non-restraint is in fashion, but is it not abused by being pushed too far ? How long will it be before we have the inevitable reaction? When a patient is prevented from injuring himself or others by being forcibly held by anyone, he usually has the spirit of opposition raised within him and struggles to be free; the then necessary pressure upon his arms may cause bruises, easily produced and tardy to disappear, but he is restrained quite as much as, or more than, if he had worn some special garment ; still, it is not " restraint" requiring to be entered in the Case Book and Medical Journal, and so manual restriction is preferred to mechanical, by which a patient cannot injure himself or others if he be guarded by an attendant.

Some persons appear to entertain a morbid aversion to the use of any mechanical restraint; it used to be so much abused that they seem to dread it could be again, notwithstanding the close inspection the autho-

* Read before the Psychological Section at the Annual Meeting of the British Medical Association in Birmingham, August 1872 . rities exercise so carefully, and the absence now of all privacy concerning the treatment of the insane. Those who advocate non-restraint at any cost err most needlessly, if they imagine mechanical restraint can be again abused; the honesty, humanity, skill, and watchfulness of British asylum superintendents are sufficient guarantees against so sad a relapse, even if the supervision of the authorities, central and local, were relaxed, and if the importance of medical and public opinion, as expressed by the press, ceased to be duly estimated.

In no case where it can be avoided without harm to the patient should restraint be resorted to; but in some few and otherwise unmanageable cases of suicidal melancholia, of excessive and dangerous violence, it is better to employ some appliance than frequent manual, antimonial, or narcotic means. The "moral" effect produced on a wilfully aggressive or destructive patient by the use of gloves or the camisole is often most salutary and valuable; he finds he can do no harm, and ceases to be a source of apprehension and danger; he feels he is conquered, and is reduced to the similitude of a thrashed bully.

With regard to the curability of the patients, is it not infinitely preferable to see an occasional, but only when really necessary, use of mechanical restriction than to find sedatives, or nauseating doses of antimony, given for the purpose of quieting the patients? By the use of the latter, it may be charmingly easy to keep the obnoxious word "restraint" out of Case-Books and Reports, and the patients can be very much less troublesome, noisy, and expensive; but they are also more incurable. It is better to have curable patients with the censure, if such must be, than incurable ones with the commendation of the authorities and journalists. The medical Commissioners in Lunacy are practical men, experienced in the difficulties met with in the treatment of exceptional cases, and, although adverse to the principle of corporeal restraint, are just, and tolerate it when its necessity and circumstances have been indicated and duly reported. Every physician treating an insane person must consider, "What is best for the patient?" and answer the question in accordance with his resources, and conscientiously; otherwise, he fails in his manifest duty.

\section{NECROSIS OF THE CLAVICLE IN A CHILD.*}

By JAMES THOMPSON, M.B., Leamington.

IN April of the present year, I was called to see a child aged 4 yearsthe last surviving child of a family of six children-of delicate appearance, and with evident constitutional taint. There was no history of any injury. The child complained of pain referred to the sternal end of the clavicle; the joint was swollen and red, and had been so for twenty-four hours before I was called to see it. Movement of the head caused much pain, but the child freely moved the arm herself; the whole clavicle was tender to the touch, and the swelling spread towards the acromial end. The diagnosis given at the time was fracture of the clavicle, with some laceration of the sterno-clavicular joint. It seemed most likely that by some slight and unrecorded injury the bone had been fractured in a child with a scrofulous diathesis and history. The ordinary bandage was applied, and a cold lotion over the seat of injury. This appeared to cause much discomfort, and the child wriggled off the bandage, and moved the arm freely. The swelling and tenderness continued, and three days afterwards there was a severe rigor, with subsequent high temperature (106 deg. in axilla), which pointed to the formation of matter. An abscess formed, which was opened when ripe, and a large quantity of pus evacuated. The child was so restless that it was quite impossible to pass a probe into the abscess to investigate the cause of the formation. Dr. Carter saw the case with me, and after consultation we agreed to poultice and support the child's health, and wait the issue. The general health of the child improved greatly, but the local tenderness continued, and a guarded prognosis was given, stating that under the circumstances it was quite impossible to say what was the actually injured part. The abscess continued to discharge for nearly three weeks, during which time the child could not be induced to keep the arm quiet. I had now quite made up my mind that it was diseased bone with which I had to deal, and I requested permission from the parents to use chloroform, but this was refused ; palliatives, stimulants, and support were all that was left. Another week passed over, and then another rigor took place, and another abscess formed one-and-a-half inches below the sterno-clavicular joint. This was opened, and another quantity of matter was evacuated with relief to the general symptoms; three days afterwards I fancied I felt loose bone (with

* Read before the Surgical Section at the Annual Meeting of the British Medical Association in Birmingham, August 1872. 